\title{
RENDIMENTO EM MADEIRA SERRADA DE Pinus taeda PARA DUAS METODOLOGIAS DE DESDOBRO
}

\author{
Mauro Itamar Murara Junior*, Márcio Pereira da Rocha**, Romano Timofeiczyk Junior*** \\ *Eng. Florestal, M.Sc., Escola Técnica Superior Tupy - mauroimbira@zipmail.com.br \\ **Eng. Florestal, Dr., Depto. de Engenharia e Tecnologia Florestal da UFPR - mprocha@floresta.ufpr.br \\ ***Eng. Florestal, Dr., Depto. de Economia Rural e Extensão da UFPR - romano@floresta.ufpr.br \\ Recebido para publicação: 18/06/2004 - Aceito para publicação: 10/06/2005
}

\begin{abstract}
Resumo
Rendimento em madeira serrada de Pinus taeda para duas metodologias de desdobro. Este trabalho teve o objetivo de avaliar o rendimento em madeira serrada de Pinus taeda com duas diferentes metodologias de desdobro, denominadas de sistema convencional e sistema otimizado, utilizando 100 toras com diâmetros entre 18 e $44 \mathrm{~cm}$. As 100 toras foram agrupadas em cinco classes diamétricas com 20 toras, sendo essas divididas em igual número para cada sistema de desdobro No desdobro convencional, o rendimento variou de $35,24 \%$ a $43,92 \%$, e no desdobro otimizado, de $41,65 \%$ a $63,04 \%$. O rendimento foi afetado pelo sistema de desdobro utilizado. No desdobro convencional, não houve tendência de aumento do rendimento com o aumento do diâmetro das toras. No desdobro otimizado o rendimento foi maior em todas as classes e apresentou a tendência de aumentar com o aumento do diâmetro das toras. A classificação de toras e modelos de corte para cada classe diamétrica (desdobro otimizado) foi uma forma eficiente para aumentar o rendimento em madeira serrada de pinus.

Palavras-chave: Pinus; classificação de toras; modelos de corte; otimização.
\end{abstract}

\section{Abstract}

Sawnwoodyield of Pinus taeda for two log sawing methodologies. This work was developed to evaluate the sawnwoodyield of Pinus taeda with two differents methodologies of log sawing called conventional and optimized systems, for a hundred logs with diameters between 18 and $44 \mathrm{~cm}$. The logs were grouped in five diameter classes with twenty logs by class. The half of them were divided in the same number for each sawing system. In the conventional sawing the yield ranged from $35,24 \%$ to $43,92 \%$, while in optimized sawing the variation was from $41,65 \%$ to $63,04 \%$. The yield was affected by the sawing system used. In conventional sawing, do not have on increase tendency of yield with the logs' diameter raise. In optimized sawing system the yield was greater in all classes and showed the tendency of increasing with logs' diameter raise. The logs' selection and sawing models used to each diameter class (optimized sawing) were efficient methods to increase the yield in sawnwood of pine.

Keywords: Pine; logs classification; sawn models; optimization.

\section{INTRODUÇ̃̃O}

Ao longo das últimas décadas, o perfil de consumo de madeiras oriundas de reflorestamento mudou substancialmente em função das restrições de exploração e da disponibilidade de espécies florestais nativas. A cadeia produtiva estendeu-se para as essências de rápido crescimento, plantadas e manejadas. A grande concentração de plantios de pinus é a região Sul do Brasil, especificamente os estados do Paraná e Santa Catarina, onde as espécies mais plantadas são Pinus elliottii e Pinus taeda.

A madeira de pinus exerce importante papel no fornecimento de matéria-prima para indústrias de papel e papelão, laminados, compensados e indústria moveleira. Devido ao elevado consumo que tem ocorrido na região Sul do Brasil nos últimos anos, a procura pela matéria-prima pinus aumentou, conseqüentemente diminuindo sua oferta no mercado. Dessa forma, surgiu a necessidade de se otimizar o 
processo de desdobro das toras quando o produto final tem finalidade para a indústria de serrados e moveleira.

O rendimento em madeira serrada é influenciado por diversos fatores, tais como características da espécie, produtos, maquinário, mão de obra e, principalmente, pelo diâmetro das toras. Além desses fatores, o tratamento que é dado às toras ainda no pátio da serraria e outras decisões de como desdobrá-las são fatores fundamentais para que se atinjam bons níveis de rendimento.

$\mathrm{O}$ volume de resíduos gerados pode-se expressar como a diferença entre o volume de madeira em toras que entra na serraria e o volume de madeira serrada produzida. A maior quantidade de resíduos gerados é por ocasião do desdobro primário e secundário das toras. Considerando-se os resíduos gerados pelo processo produtivo, como cascas, costaneiras, refilos, aparas e serragem, seria irracional não promover o aproveitamento máximo desses subprodutos do beneficiamento primário da madeira. Tais resíduos, em um primeiro momento, são tidos como rejeitos no processo, mas seguramente podem sair da serraria como matéria-prima para produção de pasta e celulose e chapas de composição, bem como promover a auto-suficiência energética da própria indústria (Fontes, 1994).

Um sistema de desdobro convencional consiste em se desdobrar toras sem classificação e sem uma definição exata de um modelo de corte para cada classe diamétrica. Tal condição, na maioria das vezes, induz a um baixo aproveitamento da tora, propiciando uma maior geração de subprodutos, muitas vezes considerados resíduos do processo (Rocha, 2002). O Brasil ainda possui um grande número de serrarias que utilizam o sistema convencional de desdobro, em que as toras são desdobradas de acordo com critérios escolhidos pelo operador da máquina principal, ou seja, é ele quem define a melhor maneira de se desdobrar uma tora. Dessa maneira, podem ocorrer elevadas perdas de matéria-prima, devido à ausência de tecnologias apropriadas para o desdobro das toras, encarecendo o processo, em função de que há a necessidade de se consumir maior volume de matéria-prima para produzir a mesma quantidade de produto serrado.

A escolha dos operadores da serra principal, resserradeiras, canteadeiras e destopadeiras assume verdadeira importância, tendo em vista que esses operadores estão continuamente tomando decisões que dizem respeito a fatores que dependem do bom funcionamento das máquinas, que, por sua vez, afetam o desempenho da indústria: produtividade, qualidade do produto e o elevado índice de retrabalho para recuperação da matéria-prima. A decisão pessoal de um operador de como secionar um tronco ou mesmo desdobrar dificilmente obterá um nível ótimo, isso porque ele raramente conseguirá obter a melhor visualização de todas as alternativas no pouco tempo que tem para tomada de decisões (Leite, 1994). Assim, é indicado o emprego de modelos de pesquisa operacional. Em geral, os erros mais comuns observados são os excessos de espessura das costaneiras, incorreta seleção do corte radial e subdimensionamento na largura e comprimento das peças.

Quando se trata de madeira reflorestada, como o caso do pinus, os diâmetros das toras diminuem e se homogeneizam, o que facilita a utilização de técnicas de otimização no desdobro. Dessa forma, uma classificação eficiente e o estabelecimento de modelos de corte apropriados irão proporcionar bons resultados na serraria. Trata-se de uma maneira de se conduzir o desdobro de toras através da sua otimização. Nesse caso, as toras são classificadas e, muitas vezes, descascadas e desdobradas dentro de um modelo de corte pré-definido para cada classe diamétrica, caracterizando-se um processo de otimização das toras. Um sistema de desdobro otimizado constitui em utilizar um sistema de corte anteriormente estudado, objetivando a máxima utilização da tora (Leite, 1994).

As perspectivas de crescimento no consumo de toras de pinus no Brasil para uso industrial têm se mostrado em plena ascensão. Dessa forma, há necessidade urgente de se implantarem ações estratégicas fundamentais, para que não ocorra a estagnação da indústria madeireira (SBS, 2003).

Portanto, a necessidade de seleção de toras por classes diamétricas e o estabelecimento de diagramas de corte é de importância primária para que se consiga atingir níveis de rendimentos elevados para aquele determinado tipo de material que está sendo utilizado. Dessa maneira, é possível melhorar o rendimento em madeira serrada proporcionado por cada classe utilizada.

O objetivo desta pesquisa foi de avaliar o rendimento em madeira serrada para a melhoria do aproveitamento de Pinus taeda, através da classificação das toras e da utilização de diagramas de corte específicos para cada classe diamétrica. 


\section{MATERIAL E MÉTODOS}

\section{Local do experimento e descrição da serraria}

Este estudo foi realizado em uma serraria localizada na cidade São Bento do Sul (SC). É uma serraria de pequeno porte, com uma capacidade produtiva média em madeira serrada de $900 \mathrm{~m}^{3} / \mathrm{mês}$.

No desdobro principal, foi utilizada uma serra-fita com diâmetro de volantes de $1,25 \mathrm{~m}$ e altura de corte de $80 \mathrm{~cm}$. Para resserragem das costaneiras, utilizou-se uma serra-fita horizontal de dois cabeçotes com volantes de $1,25 \mathrm{~m}$ de diâmetro e altura de corte de $50 \mathrm{~cm}$. Para refilamento das tábuas originadas da resserragem, foram utilizadas duas serras circulares refiladeiras com altura de corte de 80 $\mathrm{mm}$. Os semiblocos obtidos no desdobro principal foram direcionados para uma serra circular múltipla com altura de corte de $110 \mathrm{~mm}$ (Figura 1).

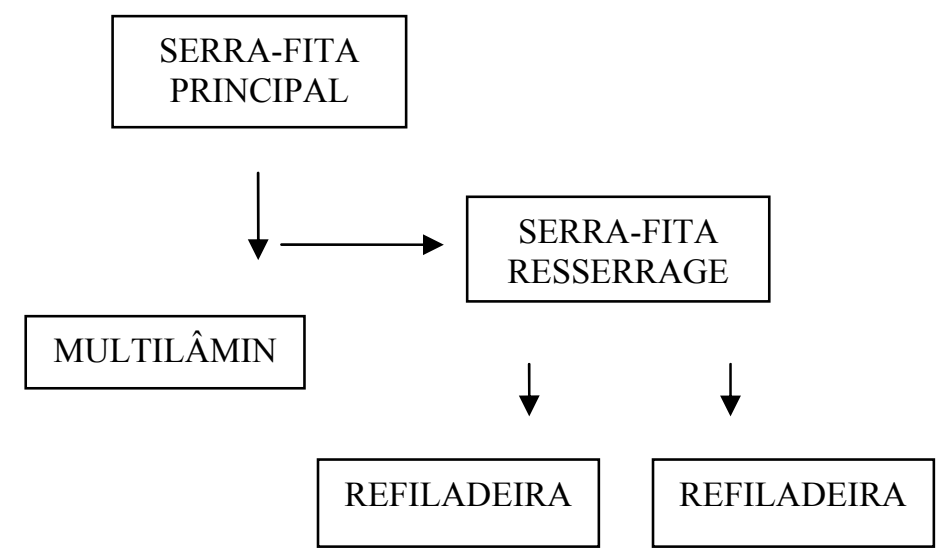

Figura 1. Layout dos equipamentos na serraria utilizados no desdobro de toras de pinus.

Figure 1. Layout of the equipments in the sawmill used in the sawing of pine's logs.

\section{Madeira utilizada}

A espécie utilizada para o estudo foi Pinus taeda, com toras de diâmetros médios entre 18 e 44 $\mathrm{cm}$, os quais foram determinados pela média aritmética dos diâmetros da ponta fina e ponta grossa, com casca. Foram utilizadas 100 toras divididas em cinco classes diamétricas, sendo 20 toras com $3 \mathrm{~m}$ de comprimento para cada classe (Tabela 1). Cada classe diamétrica foi dividida em dois lotes contendo 10 toras. O primeiro lote de toras foi submetido ao desdobro aleatório na linha de produção, utilizando o desdobro convencional adotado pela serraria. $\mathrm{O}$ segundo lote de toras foi separado nas diferentes classes diamétricas e foi desdobrado utilizando-se uma otimização de corte para cada classe, chamado de desdobro otimizado. Para ambos os lotes foram obtidos os rendimentos de madeira serrada.

Após o procedimento normal de recebimento das toras no pátio da serraria, elas foram separadas em lotes e mensuradas individualmente para obtenção do volume real.

Os diâmetros foram medidos na ponta fina (d1) e grossa (d2) das toras, sendo que o diâmetro médio (D) de cada tora foi tomado como referência, tanto para classificação diamétrica quanto para cálculo de volume. $\mathrm{O}$ comprimento das toras foi de $3 \mathrm{~m}$. Todas as toras foram mensuradas com casca. Depois de tomadas as medidas de todas as toras, para obtenção do volume real foi utilizada a seguinte equação:

$$
\mathrm{V}=\frac{\pi \mathrm{xD}}{40000}^{2} \times \mathrm{L}
$$

Onde: $\quad \mathrm{V}=$ volume da tora $\left(\mathrm{m}^{3}\right)$

$\mathrm{D}=$ diâmetro médio da tora $(\mathrm{cm})$

$\mathrm{L}=$ comprimento da tora $(\mathrm{m})$ 
Tabela 1. Classificação de toras de Pinus taeda em cinco classes diamétricas para desdobro convencional e otimizado.

Table 1. Classification of logs of Pinus taeda in five diametrical classes to sawing with conventional and optimized methods.

\begin{tabular}{lccc}
\hline Classe & No de toras & Diâmetro $(\mathbf{c m})$ & Comprimento (m) \\
\hline 1 & 20 & $18,0-24,0$ & 3,00 \\
2 & 20 & $24,1-28,0$ & 3,00 \\
3 & 20 & $28,1-34,0$ & 3,00 \\
4 & 20 & $34,1-38,0$ & 3,00 \\
5 & 20 & $38,1-44,0$ & 3,00 \\
\hline TOTAL & 100 & &
\end{tabular}

\section{Sistemas de desdobro utilizados}

As toras selecionadas e divididas em dois grupos de 10 para cada classe diamétrica foram desdobradas por duas metodologias distintas, sendo uma chamada de desdobro convencional, já utilizado pela serraria, e outra chamada de desdobro otimizado. Porém, nos dois métodos de desdobro, foram obtidas tábuas com as mesmas dimensões, sendo elas $27 \mathrm{~mm}$ de espessura e 50, 80 e $110 \mathrm{~mm}$ de largura, destinadas à confecção de painéis e outros componentes para a indústria de móveis.

O sistema de desdobro convencional utilizado pela serraria consistiu na entrada das toras classificadas para esse sistema aleatoriamente, ou seja, sem nenhuma classificação diamétrica, sendo que, na entrada da serra principal, elas eram classificadas visualmente pelo operador da máquina. Através dessa classificação visual, o operador optava pelo melhor posicionamento da tora sobre o carro porta-tora, definindo o diagrama de corte a ser desenvolvido para cada uma. Após o desdobro, todas as tábuas obtidas de cada tora, separadas em suas respectivas classes diamétricas, foram medidas para posterior obtenção dos rendimentos em madeira serrada para o sistema de desdobro convencional.

No sistema de desdobro otimizado, todas as toras foram separadas por classe diamétrica. Para cada classe diamétrica, foi definido um diagrama de corte específico, com auxílio do software otimizador e simulador de corte MaxiTora, da empresa Lindbeck Informática (Figura 2). Após a definição dos diagramas de corte, todas as toras, separadas por classes diamétricas, foram desdobradas seguindo seus respectivos diagramas de corte. Após o desdobro, todas as tábuas obtidas de cada tora, separadas em suas respectivas classes diamétricas, foram medidas para posterior obtenção dos rendimentos em madeira serrada para o sistema de desdobro otimizado.

\section{Obtenção do volume de madeira serrada}

Para o cálculo do volume de madeira serrada, todas as tábuas obtidas, separadas por tora e classe diamétrica, tiveram suas espessuras, larguras e comprimentos medidos. Foram tomadas duas medidas da espessura em dois pontos da peça (E1 e E2), sendo uma em cada topo, com auxílio de paquímetro digital. Da mesma forma, foram tomadas duas medidas da largura, uma em cada topo da tábua, com auxílio de trena. Dessa forma, foram obtidos "E" (espessura média da tábua) e "L" (largura média da tábua). O volume de cada tábua foi determinado através da fórmula:

$$
\mathrm{Vt}=\mathrm{E} \times \mathrm{L} \times \mathrm{C}
$$

Onde: $\quad \mathrm{Vt}=$ volume da tábua $\left(\mathrm{m}^{3}\right)$;

$\mathrm{E}=$ espessura média da tábua $(\mathrm{m})$;

$\mathrm{L}=$ largura da peça $(\mathrm{m})$;

$\mathrm{C}=$ comprimento da tábua $(\mathrm{m})$.

\section{Cálculo do rendimento}

O rendimento volumétrico, também chamado de coeficiente de serragem, coeficiente de transformação ou fator de rendimento, foi a relação entre o volume produzido de madeira serrada e o volume utilizado de madeira em forma de tora, expresso em porcentagem. 
Classe $1(18-24 \mathrm{~cm})$
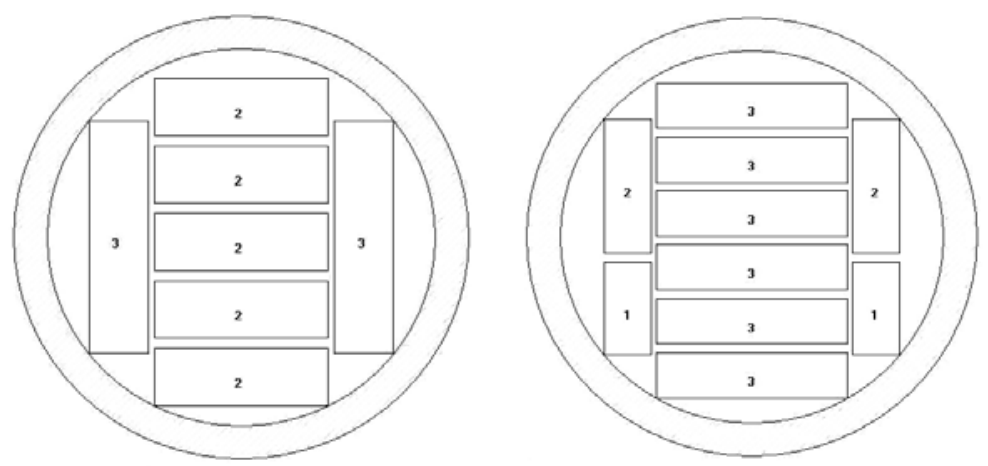

Classe $3(28,1-34 \mathrm{~cm})$

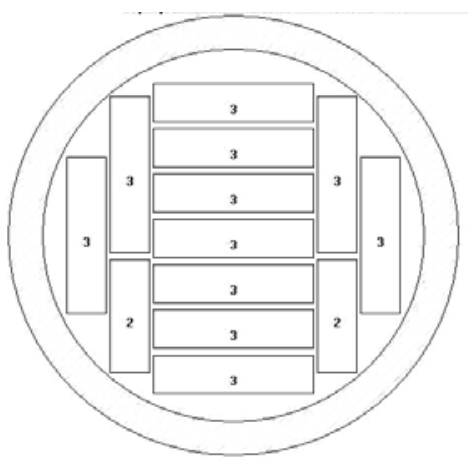

Classe $4(34,1-38 \mathrm{~cm})$
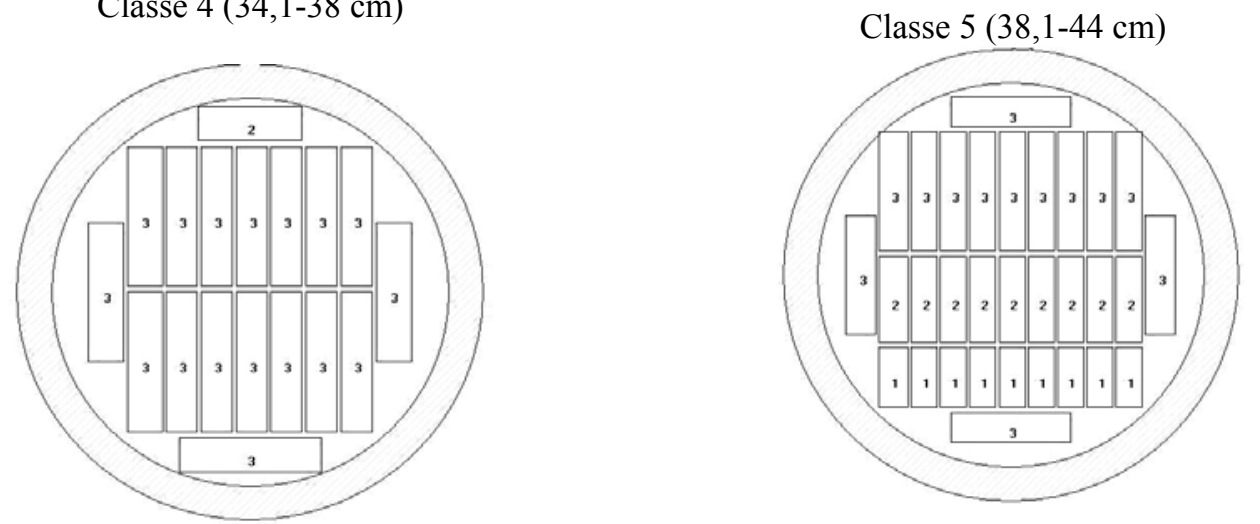

Figura 2. Otimização de corte estabelecida para o sistema de desdobro otimizado de toras de Pinus taeda distribuídas em cinco classes diamétricas no sistema de desdobro otimizado.

Figure 2. Optimization sawing established to optimized saw system to logs of Pinus taeda distributed in five diametrical classes in the optimized sawing system.

Legenda: Anel externo - casca; Tábua 1 - 27 x 50 mm; Tábua 2 - 27 x 80 mm; Tábua 3 - 27 x 110 mm.

Após os processos de desdobro, todas as peças obtidas por classe diamétrica que tinham seus topos pintados com cores diferentes, para facilitar a separação dos lotes, foram medidas e agrupadas segundo suas respectivas cores. Para mensurar o rendimento de cada lote, foi utilizada a seguinte fórmula:

$$
R \%=\frac{\sum V t}{\sum V} \times 100
$$

Onde: $\mathrm{R} \%=$ rendimento em madeira serrada obtida de um lote (\%);

$\sum \mathrm{Vt}=$ somatória dos volumes de todas as tábuas serradas no lote $\left(\mathrm{m}^{3}\right)$;

$\sum \mathrm{V}=$ somatória dos volumes de todas as toras do lote $\left(\mathrm{m}^{3}\right)$.

\section{Análise estatística}

O delineamento experimental utilizado foi inteiramente casualizado, disposto em fatorial, sendo os fatores a classificação, com dois níveis, e as classes diamétricas, com cinco níveis (cinco classes), com dez repetições. O efeito da classificação das toras foi considerado como qualitativo, e a classe diamétrica como quantitativa. Foi utilizado para as análises o centro da classe. 


\section{RESULTADOS E DISCUSSÃO}

\section{Desdobro convencional}

$\mathrm{Na}$ tabela 2, são apresentados os resultados de rendimento médio para as cinco classes estudadas, quando utilizado o desdobro convencional.

A classe 1 apresentou o menor rendimento médio (37,03\%), o que era esperado, por se tratar da classe com os menores diâmetros. Segundo Rocha (2000), é normal, em serrarias, as toras de menores diâmetros apresentarem menores rendimentos. Porém, ao desdobrar Eucalyptus grandis em duas classes diamétricas (19 a $25 \mathrm{~cm}$ e 25 a $30 \mathrm{~cm}$ ), o autor obteve um rendimento médio superior para a classe de menores diâmetros. Analisando-se as classes seguintes, pode-se observar que as classes 2, 3, 4 e 5 apresentaram rendimentos médios muito próximos, sendo que o menor foi para a classe $3(45,31 \%)$ e o maior para a classe $5(46,75 \%)$. Os maiores rendimentos médios ocorreram nas maiores classes diamétricas, ou seja, 4 e 5.

Tabela 2. Volumes de toras e de madeira serrada de Pinus taeda com seus respectivos rendimentos obtidos pelo método de desdobro convencional.

Table 2. Logs and sawnwood's volumes of Pinus taeda with its respectives yields obtained by conventional sawing method.

\begin{tabular}{|c|c|c|c|c|c|}
\hline \multirow{2}{*}{ Classe } & \multirow{2}{*}{ № Toras } & \multicolumn{2}{|c|}{ Volume $\left(\mathbf{m}^{3}\right)$} & \multirow{2}{*}{ Rendimento (\%) } & \multirow{2}{*}{ CV (\%) } \\
\hline & & Toras & Serrado & & \\
\hline 1 & 10 & 1,05 & 0,39 & $37,03 a$ & 2,54 \\
\hline 2 & 10 & 1,75 & 0,79 & $45,35 b$ & 2,29 \\
\hline 3 & 10 & 2,16 & 1,18 & $45,31 b$ & 2,69 \\
\hline 4 & 10 & 3,48 & 1,63 & $46,75 b$ & 1,88 \\
\hline 5 & 10 & 6,02 & 2,81 & $46,62 b$ & 5,30 \\
\hline MÉDIA & & 2,89 & 1,36 & 44,21 & \\
\hline
\end{tabular}

Em função da grande amplitude diamétrica existente entre as classes 2 e 5, era esperado que houvesse uma diferença entre os rendimentos das classes. Esse resultado é um forte indício de que através desse procedimento de desdobro, sem classificação das toras e sem um modelo de corte específico para cada uma delas, o aproveitamento tornou-se inadequado, não resultando num rendimento satisfatório. Outro fator que deve ser levado em consideração é a pequena variedade de produtos obtidos das toras, o que pode fazer com que algumas classes diamétricas não sejam adequadas para as tábuas que se deseja obter delas.

Comparando-se as classes 1 e 2 com pesquisa realizada por Fontes (1994), que também utilizou o desdobro convencional, observa-se que ambas as classes apresentaram rendimentos médios superiores aos encontrados pelo autor, que, ao utilizar toras com classes diamétricas variando de 15 a $29,5 \mathrm{~cm}$ de diâmetro, obteve um rendimento médio de 30,47\%. Provavelmente, o autor obteve um resultado pouco satisfatório por estar avaliando uma classe diamétrica com uma amplitude elevada. Em contrapartida, Ribas et al. (1989), testando classes com diâmetros entre 21,1 e $24 \mathrm{~cm}$, obtiveram um rendimento de $48,50 \%$, superior ao obtido para a classe 1 .

Vianna Neto (1984), estudando técnicas de desdobro em serrarias que utilizam toras com pequenos diâmetros, concluiu que o rendimento de madeira serrada aumentou de acordo com o incremento no diâmetro das toras utilizadas, no qual a qualidade da matéria-prima pode influenciar em até $70 \%$ no êxito da obtenção de um ótimo rendimento. Da mesma forma, estudando a influência do diâmetro no rendimento em madeira serrada, o autor afirma que ele exerce uma influência diretamente proporcional.

Analisando-se a diferença estatística entre as cinco classes (Tabela 2), observa-se que houve uma diferença significativa entre a classe 1 e as classes 2, 3, 4 e 5, porém, entre estas não foi observada nenhuma diferença significativa. Pode-se observar que, mesmo existindo uma amplitude diamétrica de 20 $\mathrm{cm}$ entre as classes 2 e 5, a diferença entre elas foi muito pequena, variando de 45,35\% (classe 2) a $46,62 \%$ (classe 5), perfazendo uma diferença de 1,4 pontos percentuais entre elas. 
Ribas et al. (1989), estudando a influência do diâmetro e do comprimento de toras de pinus no rendimento em madeira serrada, encontraram aumento significativo a partir de classes diamétricas acima de $21 \mathrm{~cm}$. Os autores obtiveram um aumento significativo no rendimento com toras a partir de $24,1 \mathrm{~cm}$ de diâmetro, não ocorrendo maiores incrementos no rendimento com toras acima de $28,1 \mathrm{~cm}$.

As toras utilizadas para a classe 2, as quais possuíam diâmetros entre 24,1 e $28 \mathrm{~cm}$, resultaram em um rendimento médio de 45,14\%, superior ao resultado encontrado por Fontes (1994), que foi de 33,73\%.

Ribas et al. (1989) trabalhando com classes de 24,1 a $27 \mathrm{~cm}$, obtiveram um rendimento superior para essa classe $(51,41 \%)$, atribuindo os valores obtidos a uma menor amplitude diamétrica utilizada ou outros fatores de grande importância no rendimento, como a idade do povoamento, a qualidade das toras e os produtos obtidos, associados a um modelo de desdobro mais adequado às classes diamétricas. Olandoski et al. (1998), utilizando toras com 23,0 a 27,9 cm de diâmetro, obtiveram rendimento médio de madeira serrada de $51,97 \%$, porém os autores utilizaram o sistema de desdobro tangencial em sanduíche, no qual todas as tábuas obtidas da tora foram refiladas na maior largura possível. Já neste estudo, todas as toras foram desdobradas de maneira a proporcionar tábuas em somente três larguras pré-definidas. Acosta (1999), estudando desdobro convencional através do sistema tangencial em sanduíche, porém utilizando toras de Eucalyptus de 20 a $25 \mathrm{~cm}$ de diâmetro, obteve um rendimento médio de $53 \%$. Nesse caso não se pode descartar a diferença entre as espécies, pois este é um fator de grande importância no rendimento em madeira serrada.

A classe 3, com toras de diâmetros entre 28,1 e $34 \mathrm{~cm}$, apresentou um rendimento médio de $45,31 \%$. Comparando-se com a classe 2, pode-se observar que não aconteceu o que era esperado, ou seja, essa classe apresentar rendimento superior à classe 2, com toras de diâmetros menores. Acosta (1999), estudando desdobro convencional através do sistema tangencial em sanduíche de toras de Eucalyptus com diâmetros entre 25 e $30 \mathrm{~cm}$, obteve rendimento de 54\%. Olandoski et al. (1998), ao avaliarem o rendimento de toras de Pinus spp. com diâmetros entre 28 e $32,9 \mathrm{~cm}$, obtiveram um rendimento de madeira serrada de 53,09\%. Esses resultados são um indicativo de que o sistema de desdobro convencional utilizado neste estudo não proporcionou um rendimento satisfatório (Tabela 2).

As classes 4 e 5, em comparação com as classes 2 e 3, não apresentaram crescimento significativo no rendimento de madeira serrada, sendo que a classe 5, que utilizou os maiores diâmetros (38 a $44 \mathrm{~cm}$ ), apresentou uma diferença de rendimento de 0,13 ponto percentual a menos que a classe 4 (Tabela 2).

Os resultados encontrados na Tabela 2 indicam que a utilização de toras com maiores diâmetros não influenciou diretamente no rendimento em madeira serrada, o que evidencia que a utilização do desdobro convencional não surtiu um bom resultado em termos de rendimento no desdobro de toras com diâmetros elevados. Dessa forma, no que diz respeito a um melhor rendimento, torna-se indiferente desdobrar toras com diâmetros entre 24,1 a $28 \mathrm{~cm}$ ou toras com 38 a $44 \mathrm{~cm}$.

\section{Desdobro otimizado}

Observa-se, na tabela 3, que os rendimentos médios encontrados para madeira serrada utilizando otimização de corte variaram de 44,93\% a 63,58\%, gerando uma média de 53,60\%. Esses valores foram superiores aos obtidos no desdobro convencional (Tabela 2) e todas as classes apresentaram incremento em seus rendimentos médios, quando realizada a seleção das toras e utilizado um diagrama otimizado para cada classe diamétrica.

Através da análise da tabela 3 , além do aumento do rendimento médio para todas as classes diamétricas em relação ao desdobro convencional, observa-se que, de acordo com o aumento do diâmetro das toras, os rendimentos médios também aumentaram. Estatisticamente e ao contrário do desdobro convencional, todas as classes diferiram entre si.

Esses resultados obtidos através da otimização de corte estão de acordo com Freitas (1986), que, estudando técnicas de desdobro em serrarias que utilizam toras com pequenos diâmetros, concluiu que o índice de rendimento de madeira serrada aumenta de acordo com o incremento no diâmetro das toras utilizadas, assim como Vianna Neto (1984), o qual afirma que o diâmetro influencia diretamente o rendimento em madeira serrada.

Biasi e Rocha (2003), desdobrando toras de Pinus elliottii variando de $8 \mathrm{~cm}$ até $45 \mathrm{~cm}$ de diâmetro e utilizando diagramas de corte para as classes selecionadas, obtiveram um rendimento médio para as mesmas de $43,17 \%$, o que foi inferior à média de $53,60 \%$ obtida nesta pesquisa. Porém, as classes 
de maior amplitude e as toras abaixo de $18 \mathrm{~cm}$ de diâmetro, utilizadas pelos autores, proporcionaram a queda na média do rendimento obtido (Tabela 3 ).

Tabela 3. Volume de toras e madeira serrada de Pinus taeda com seus respectivos rendimentos obtidos pelo método de desdobro otimizado.

Table 3. Logs and sawnwood's volumes of Pinus taeda with its respectives yields obtained by optimized sawnwood method.

\begin{tabular}{|c|c|c|c|c|c|}
\hline \multirow{2}{*}{ Classe } & \multirow{2}{*}{ № Toras } & \multicolumn{2}{|c|}{ Volume $\left(\mathbf{m}^{3}\right)$} & \multirow{2}{*}{ Rendimento (\%) } & \multirow{2}{*}{ CV (\%) } \\
\hline & & Toras & Serrado & & \\
\hline 1 & 10 & 1,15 & 0,52 & $44,93 a$ & 2,67 \\
\hline 2 & 10 & 1,53 & 0,73 & $48,02 \mathrm{~b}$ & 2,55 \\
\hline 3 & 10 & 2,28 & 1,21 & $53,24 \mathrm{c}$ & 2,30 \\
\hline 4 & 10 & 3,06 & 1,78 & $58,21 \mathrm{~d}$ & 1,45 \\
\hline 5 & 10 & 4,17 & 2,65 & $63,58 \mathrm{e}$ & 4,30 \\
\hline MÉDIA & & 2,44 & 1,38 & 53,60 & \\
\hline
\end{tabular}

A classe 1 apresentou rendimento de 44,93\% (Tabela 3). Já Biasi e Rocha (2003), utilizando otimização de corte para toras com 14 a $24 \mathrm{~cm}$ de diâmetro, ou seja, com classe de maior amplitude e toras de menores diâmetros, obtiveram rendimento de 40,17\%. Essa maior amplitude diamétrica utilizada pelos autores possivelmente tenha provocado uma subutilização das toras. Fontes (1994), estudando rendimento de madeira serrada e geração de resíduos em três diferentes serrarias, com a utilização de diagramas de corte, obteve para a classe entre 20 a $24,50 \mathrm{~cm}$ de diâmetro um rendimento médio de $30,86 \%$. Pode-se observar que mesmo com uma classe de menor amplitude diamétrica, o rendimento médio foi inferior ao obtido para a classe $1(44,93 \%)$.

A classe 2 apresentou rendimento médio de 48,02\%, superior ao obtido por Fontes (1994), que, trabalhando com toras de 25 a $29,5 \mathrm{~cm}$, obteve rendimento médio de $33,73 \%$. Para as classes 3 , 4 e 5 , a mesma tendência foi observada, culminando no maior rendimento médio obtido para a classe $5(63,58 \%)$.

\section{Comparativo entre as duas metodologias de desdobro}

A tabela 4 indica que a interação foi significativa, ou seja, o efeito do tratamento de classificação das toras e otimização de corte se alterou quando ocorreu alteração na classe diamétrica, evidenciando assim a dependência entre os fatores. Ocorreu um aumento significativo de $21,24 \%$ no rendimento em madeira serrada no desdobro otimizado em relação ao desdobro convencional.

Como a interação foi significativa, optou-se em realizar o desdobramento e avaliar o efeito entre fatores. Após o desdobramento, pôde-se observar que o efeito do tratamento foi qualitativo (Tabela 4). O tratamento utilizado para o desdobro das toras foi significativo e as classes diamétricas utilizadas também foram significativas. Os efeitos principais e a interação foram altamente significativos. Como a interação foi significativa, isso implica que os efeitos não são independentes.

Tabela 4. Análise da variância utilizando sistemas de desdobro sem classificação e com classificação diamétrica de toras de Pinus taeda.

Table 4. Analysis of the variance using sawing systems without diametrical classification and with diametrical classification of Pinus taeda logs.

\begin{tabular}{|c|c|c|c|c|}
\hline Fonte de Variação & G.L. & SQ & QM & $\mathbf{F}$ \\
\hline Classificação(C) & 1 & 2150,1769 & 2150,1769 & $90,79 * *$ \\
\hline Classe Diamétrica(D) & 4 & 2328,1312 & 582,0328 & $24,576^{* *}$ \\
\hline $\mathrm{C} \times \mathrm{D}$ & 4 & 528,7744 & 132,1936 & $5,582 * *$ \\
\hline Resíduo & 90 & 2131,4635 & 26,6829 & \\
\hline Total & 99 & 7138,5460 & & \\
\hline $\mathrm{CV}$ & 9,96 & & & \\
\hline Média Geral & 48,8518 & & & \\
\hline $\mathrm{N}^{0}$ observações & 100 & & & \\
\hline
\end{tabular}


O desdobro da classe 1, utilizando a otimização de corte, mostrou que os sistemas utilizados diferiram estatisticamente, ocorrendo um acréscimo de $21,33 \%$ no rendimento médio em madeira serrada ao passar-se do sistema de desdobro convencional para o sistema de desdobro otimizado (Tabela 5).

A classe 2 foi a única classe de toras que não apresentou diferença significativa entre os sistemas de desdobro testados. Porém, mesmo não diferindo estatisticamente, essa classe apresentou um ganho de $5,89 \%$ no rendimento de madeira serrada ao passar do desdobro convencional para o desdobro otimizado. Levando-se em conta que toras de 24 a $28 \mathrm{~cm}$ de diâmetro são as mais utilizadas nas indústrias de madeira serrada de pinus, essa diferença de aproximadamente $6 \%$ pode justificar a implantação de sistemas de classificação de toras e programações de corte em serrarias de grande porte, cabendo para isso uma análise econômica adequada.

Como a classe 1, as classes 3, 4 e 5 também diferiram estatisticamente nos dois sistemas de desdobro utilizados. Entretanto, as classes 5 e 4 foram as que obtiveram o melhor desempenho com a utilização do desdobro otimizado. A classe 5 apresentou um ganho de aproximadamente $36 \%$ no rendimento em madeira serrada. Esse resultado mostra claramente como o desdobro convencional subutilizou as toras nessa classe. O mesmo aconteceu na classe 4, em que ocorreu um acréscimo no rendimento médio entre os dois sistemas de $24,51 \%$ (Tabela 5).

Tabela 5. Comparação do rendimento em madeira serrada de Pinus taeda entre desdobro convencional e desdobro otimizado para cinco classes diamétricas.

Table 5. Comparison of yield in sawnwood of Pinus taeda between conventional and optimized sawing for five diametrical classes.

\begin{tabular}{cccc}
\hline Classe & $\begin{array}{c}\text { Rendimento desdobro } \\
\text { convencional (\%) }\end{array}$ & $\begin{array}{c}\text { Rendimento desdobro } \\
\text { otimizado (\%) }\end{array}$ & Aumento (\%) \\
\hline 1 & $37,03 \mathrm{a}$ & $44,93 \mathrm{~b}$ & 21,33 \\
2 & $45,35 \mathrm{a}$ & $48,02 \mathrm{a}$ & 5,89 \\
3 & $45,31 \mathrm{a}$ & $53,24 \mathrm{~b}$ & 17,50 \\
4 & $46,75 \mathrm{a}$ & $58,21 \mathrm{~b}$ & 24,51 \\
5 & $46,62 \mathrm{a}$ & $63,58 \mathrm{~b}$ & 36,38 \\
\hline MÉDIA & 44,21 & 53,60 & 21,12 \\
\hline
\end{tabular}

Médias seguidas de mesma letra, em cada linha, não diferem estatisticamente pelo teste de Tukey em nível de $95 \%$ de probabilidade.

A tendência da linearidade no aumento do rendimento em madeira serrada pode ser observada na figura 3, na qual também se pode observar a amplitude no ganho percentual em rendimento para as cinco classes estudadas, evidenciando o desempenho da classificação das toras e otimização de corte.

Observa-se, na figura 3, que as duas classes de maiores diâmetros foram as que apresentaram maior incremento no rendimento, quando utilizado o sistema de desdobro otimizado. Pode-se dizer que, em se tratando de toras de grandes diâmetros para serrarias de pinus, essas duas classes dificilmente são destinadas à produção de madeira serrada, pois, devido ao seu custo, normalmente destinam-se à produção de madeira laminada. Dessa forma, dependendo da necessidade de uso dessa matéria-prima em serrarias, o desdobro convencional, ou seja, sem classificação e sem um diagrama de corte otimizado, pode tornar-se inviável o uso dessas toras. Porém, cabe para isso uma análise de custos.

Em relação à classe 2, em função de não ter apresentado diferença estatística entre as duas metodologias de desdobro, pode-se dizer que essa classe é a mais adequada para a obtenção das tábuas testadas, tendo em vista que a diferença entre as duas metodologias foi considerada pequena em relação às outras classes diamétricas (Figura 3 ).

\section{CONCLUSÕES E RECOMENDAÇÕES}

De acordo com os resultados obtidos, conclui-se que:

- A comparação entre os dois sistemas de desdobro estudados evidenciou que o rendimento médio obtido no sistema otimizado foi $21,1 \%$ maior que o sistema convencional utilizado nas serrarias de pinus.

- Dentro das classes diamétricas, o desdobro otimizado apresentou um aumento no rendimento de 
madeira serrada, exceto na classe de 24,1 a $28,0 \mathrm{~cm}$, onde não foi detectada diferença significativa entre os sistemas estudados.

- A maior diferença no rendimento médio em madeira serrada entre os sistemas de desdobro convencional e otimizado foi obtida na classe diamétrica de 38,1 a $44,0 \mathrm{~cm}$.

- No sistema de desdobro otimizado, observou-se um maior rendimento médio à medida que aumentou o diâmetro das toras, tendência que não foi observada no desdobro convencional.

- A classificação das toras e o estabelecimento de modelos de corte para cada classe diamétrica foi uma forma eficiente de se aumentar o rendimento em madeira serrada de pinus.

Com base nas conclusões aqui apresentadas, recomendam-se:

- Implantação de sistema de classificação e seleção das toras em serrarias de pinus de acordo com padrões estabelecidos e testados neste estudo.

- Utilização do sistema de desdobro otimizado testado neste estudo, respeitando os limites das classes diamétricas e diagramas de corte propostos.

- Realização de testes com classes diamétricas de menores amplitudes.

- Testagem de outros possíveis diagramas de corte com classes diamétricas de menores amplitudes.

- Realização de estudos de eficiência da serraria, relacionando-os com os rendimentos obtidos.

- Avaliação econômica comparativa dos sistemas de desdobro estudados, visando a viabilidade de sua aplicação no processamento de madeira de pinus.

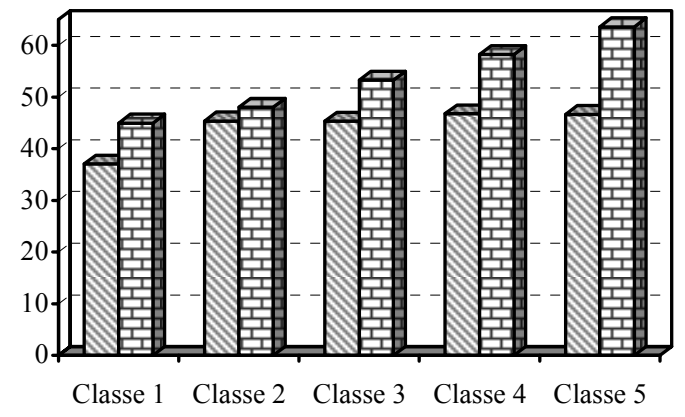

QDesdobro convencional $\mathbf{\square}$ Desdobro otimizado

Figura 3. Comparativo entre rendimento em madeira serrada de Pinus taeda para cinco classes diamétricas e duas metodologias de desdobro.

Figure 3. Comparison between yield in sawnwood of Pinus taeda for five diametrical classes and two sawing methodologies.

\section{REFERÊNCIAS}

ACOSTA, M. S. Experiência Argentina em la Producción de la Madeira de Eucalipto, Panorama a 1999. In: WORKSHOP TÉCNICAS DE ABATE, PROCESSAMENTO E UTILIZAÇÃO DA MADEIRA DE EUCALIPTO, 1999, Viçosa-MG. Anais... Viçosa-MG: Universidade Federal de Viçosa, Departamento de Engenharia Florestal, 1999.

BIASI, C.; ROCHA, M. P. Rendimento em serraria de Pinus elliottii. In: CONGRESSO FLORESTAL BRASILEIRO, 8., 2003, São Paulo. Anais... São Paulo: [s.n.], 2003.

FONTES, P. J. P. Auto-suficiência energética em serraria de Pinus e aproveitamento dos resíduos. Curitiba, 1994. 104f. Dissertação (Mestrado em Engenharia Florestal) - Setor de Ciências Agrárias, Universidade Federal do Paraná. 
FREITAS, A. R. Alternativas tecnológicas para melhor aproveitamento dos recursos florestais brasileiros. Silvicultura, São Paulo, v. 11, n. 41, p. 176-178, 1986. CONGRESSO FLORESTAL BRASILEIRO, 5. , 1986, Olinda.

LEITE, H. G. Conversão de troncos em multiprodutos da madeira, utilizando programação dinâmica. Viçosa, MG, 1994. 230p. Tese (Doutorado em Ciência Florestal) - Universidade Federal de Viçosa.

OLANDOSKI, D. P.; BRAND, M. A.; ROCHA, M. P. Avaliação do rendimento em madeira serrada, qualidade e quantidade de resíduos no desdobro de Pinus spp. Revista do Setor de Ciências Agrárias, Curitiba, v. 17, n. 1-2, 1998.

RIBAS, C. et al. Estudo da influencia do diâmetro e do comprimento das toras de Pinus elliottii na produção de madeira serrada e de resíduos de serraria. Revista Instituto Florestal, São Paulo, p. 51-65, 1989.

ROCHA, M. P. Eucalyptus grandis Hill ex Maiden e Eucalyptus dunnii Maiden como fontes de matéria prima para serrarias. Curitiba, 2000. 185f. Tese (Doutorado em Engenharia Florestal) - Setor de Ciências Agrárias, Universidade Federal do Paraná.

ROCHA, M. P. Técnicas e planejamento em serrarias. Série Didática Fupef, Curitiba, 02/01, 121p., 2002

SBS. Disponível em: <http://www.sbs.com.br> Acesso em 12 dez. 2003.

VIANNA NETO, J. A. Considerações básicas sobre desdobro de Pinus spp. Silvicultura, São Paulo, v. 9, n. 34, p.15-19, 1984. SEMADER - Seminário sobre processamento e utilização de madeiras de reflorestamento, 1., 1984 São Paulo. 